\title{
Small hive beetles are facultative predators \\ of adult honey bees
}

Christian W.W. Pirk ${ }^{1 *}$, Peter Neumann ${ }^{1,2}$

${ }^{1}$ Department of Zoology and Entomology, University of Pretoria, 0002 Pretoria, South Africa

${ }^{2}$ Swiss Bee Research Centre, Agroscope Liebefeld-Posieux Research Station ALP Schwarzenburgstrasse $161 \mathrm{CH}-3003$ Bern Switzerland

${ }^{*}$ Author for correspondence

e-mail:CWWPirk@zoology.up.ac.za

Tel: $+27(0) 124204616$

Fax: $+27(0) 123625242$

Foraging animals can choose to act as predators or not depending on the level of defensiveness of the potential prey. This requires prior evaluation of prey defensiveness, which can be variable, e.g. young insects are usually less able to defend themselves. Here we show that small hive beetles, Aethina tumida, which are scavengers and parasites of honey bee, Apis mellifera, colonies, are facultative predators of young adult host workers. Adult female beetles mounted and attacked young workers more often than their older nestmates, indicating that the beetle is assessing the defensiveness of the host and is adjusting its behaviour accordingly. Since adult female beetles need proteins to activate their ovaries, predation on defenceless young alive host workers offers another rewarding food source, which can obviously not be exploited by beetle larvae. In conclusion, adult small hive beetles seem to be able to assess the trade-off between safety and food reward.

Key words: Apis mellifera - Aethina tumida - Behavioural plasticity - Parasite Predator - Small Hive Beetle 
Understanding the patterns and ways in which animals utilize food resources is fundamental to ecology. Animals can be categorized into herbivores, predators, omnivores, parasites and scavengers, but may show a considerable overlap between these categories depending on environmental factors, e.g. between scavengers and predators (Wilmers et al., 2003). On one hand, the obvious advantage of scavenging is that the prey cannot defend itself, implying reduced risk and lower energy expenditure for utilising such food (Foltan et al., 2005). In fact, some arthropods may prefer dead prey, such as Lithobius forficatus, (Sunderland and Sutton, 1980); Pterostichus madidus (Langan et al., 2001); Pterostichus madidus and Nebria brevicollis, (Mair and Port, 2001). On the other hand, scavenging could be less rewarding (Brown and Kotler, 2004) and consequently animals may have to trade food against safety. Indeed, juncos (Junco hyemalis) take more risks when they are hungry (Lima, 1988), and Barn Owls (Tyto alba), when hungry, show higher activity levels and are willing to take higher risks of injury (Berger-Tal et al., 2010). Furthermore, there are two examples in ants that they can adjust their prey-selection accordingly to the defensiveness of the prey, attacking rather the prey with a higher risk but greater reward (Pohl and Foitzik, 2011; Yusuf et al., 2013). Therefore, it seems adaptive when foraging animals are able to assess the defensiveness of its potential food items and therefore could trade safety for food reward or vice versa (Brown and Kotler, 2004).

Previous work has shown that the small hive beetle, Aethina tumida (Coleoptera: Nitidulidae), is a parasite and scavenger of honey bee, Apis mellifera, colonies endemic to sub-Saharan Africa (Lundie, 1940; Schmolke, 1974, cf. Hepburn and Radloff, 1998; Neumann and Härtel, 2004). Small hive beetles can further be regarded as kleptoparasites, because they are able to induce trophallactic feeding by the host (Ellis et al., 2002b). Unlike other parasites (Moritz et al., 1991), the small hive beetle faces the risk of injury when interacting with honey bee workers, because 
it is easily detected and attacked by the bees (Elzen et al., 2000; Elzen et al., 2001). Therefore, preying on individual honeybees involves the costs of overcoming the host defence and the risk of injury. Accordingly, the beetle has developed several behavioural strategies, like turtle defence posture and trophallactic mimicry, to survive within a honey bee colony (Neumann et al., 2001b; Ellis et al., 2002b; Neumann and Elzen, 2004).

Within a normal honey bee colony, beetles would encounter workers of random age and consequently of random defensiveness. Only when a honeybee colony absconds (non-reproductive swarming, (Hepburn et al., 1999; Neumann and Hepburn, 2011) one finds only callow workers left behind. Under such conditions the protein resources for the beetles are limited, especially when an African honey bee colony performs a prepared absconding (Spiewok et al., 2006) and since ovarian activation in female beetles requires proteins (Ellis et al., 2002a; Neumann et al., 2012), this clearly results in competition for proteins among the small hive beetles. Therefore, individual beetles would have to utilize every potential protein source to maximise reproductive output, therefore including scavenging on dead bees (Spiewok and Neumann, 2006). Despite efficient preparation for absconding, sealed brood, and freshly emerged workers are often left behind (Hepburn et al., 1999; Neumann and Hepburn, 2011). Honey bees, which are freshly hatched ( $<1$ day old), have still a soft chitin skeleton and cannot fly. With maturation, the skeleton hardens and the workers become more active, hence more defensive. So within any given honey bee colony, there are two distinct categories of adult workers in terms of defensiveness: less defensive callow workers and older more defensive ones. If the beetles could discriminate between these different levels of defensiveness, they could adjust their behaviour accordingly, thereby exploiting an additional food source. In case of the mature adult worker bees the beetles would refrain from attacking them since the chances of success are much lower. These costs would be the risk of 
severe injuries and the risk of death since older/ mature honey bees are more than capable to kill adult small hive beetles (Neumann et al., 2001b).

We here investigate the interactions between adult small hive beetles and the two different types of adult honey bee workers. The data show that small hive beetles are able to assess the defensiveness of their host and adjust their behaviour, by actively preying on the less defensive workers.

\section{Material \& Methods}

Experiments were conducted within the native range of small hive beetles (Neumann and Ellis, 2008) in Grahamstown, South Africa. Older workers were collected from the outer frames and freshly emerged, young workers from combs of sealed worker brood from six different queenright $A$. m. capensis colonies originating from swarms caught within the native range of the subspecies, which were placed in an incubator until adult emergence. Adult small hive beetles were reared in the laboratory according to standard protocols (Neumann et al., 2001a) and kept in boxes with cotton wool and sugar water ad libitum but without access to protein food prior to the experiments. All tested beetles emerged at least 14 days prior to the start of the experiment.

We used workers from 6 colonies and we set up 2 boxes per colony; either 20 young $(<24 \mathrm{~h})$ or 20 old workers (workers which are engaged in unloading pollen and nectar) were placed in a wooden box $\left(10 \times 20 \times 10 \mathrm{~cm}^{3}\right)$ covered with a glass lid $24 \mathrm{~h}$ before the experiment started. All boxes $(\mathrm{N}=12)$ were supplied with water and a ball of honey bread (diameter of a 1 cent $€$ coin, honey, pollen and icing sugar in a 1:1:3 ratio). Two hours before the observation started, 10 adult small hive beetles were sexed (Schmolke, 1974) and only females were added into these wooden boxes, thereby increasing the need for respective protein foraging. Therefore each experimental box consisted of 20 workers and $10 \mathrm{SHB}$, which were allowed to 
interact. The numbers were chosen to maximise the amount of interactions and were based on previous results (Elzen et al 2001). The interactions between the 10 beetles and the 20 bees were observed and recorded for $15 \mathrm{~min}$ at the beginning of every hour for 4 hours, by screening the box in a grid fashion from the upper left corner to the lower right one to avoid counting the same interaction twice (Neumann et al., 2003). The following interactions were recorded for the bees:

Ignore (within $5 \mathrm{~mm}$ of a SHB), inspect, attack (Elzen et al., 2000; Elzen et al., 2001), feeding the beetle (Ellis et al., 2002b) and flee / defend.

For the beetles the following interactions were observed:

Ignore (within $5 \mathrm{~mm}$ of a honeybee), flee, turtle-defence posture (Neumann et al., 2001b), investigate, get fed by bees, feed on dead bees, attack and mount a bee / feed on live bee (Fig 3).

We did not record the duration since we treated all interactions as instantaneous and we only recorded the above-specified behavioural patterns, which represent interactions between the workers and the SHB. To account for variation in the total number of observations, the numbers of interactions were translated into percentages for each of the 12 experimental boxes.

Due to the nature of the data, non-parametric Mann Whitney $U$ tests were used to test for significant differences in the behaviour of young and old workers towards the small hive beetles and to determine if the interactions of the beetles towards the workers were affected by the age of the worker. To quantify the effect of the SHB on the survival of the honeybee workers, we recorded the number of dead workers 24 hours after the setting up of the boxes. Fisher's exact test was used to compare the mortality between the two groups.

The boxes were kept in a incubator following standard settings (Pirk et al., 2010). For all tests the level of significances was $\alpha=0.05$ and if not stated otherwise the mean and standard deviation are given. 


\section{Results}

Old worker bees significantly more often attacked small hive beetles than their younger counterparts $(28.1 \pm 3.9 \%$ old vs. $2.1 \pm 1 \%$ young, $p<0.004)$. Moreover, small hive beetles got fed significantly more often by young than by old workers (10.1 $\pm 3.4 \%$ old vs. $31.2 \pm 3.9 \%$ young, $p<0.005$ ). There were no significant differences between old and young workers for ignoring, inspecting small hive beetles or defending themselves against small hive beetles (Fig 1). The mean number of interactions of old workers $(118.5 \pm 19.1)$ with the beetles was not significantly different than of young workers $(95.7 \pm 17.6)$ with the beetles. Of the 120 workers used in the experiment 89 of the old workers survived 24 hours, which was significantly more than the 43 in the young cohort (Fisher exact two-tailed test, $p<0.0001)$

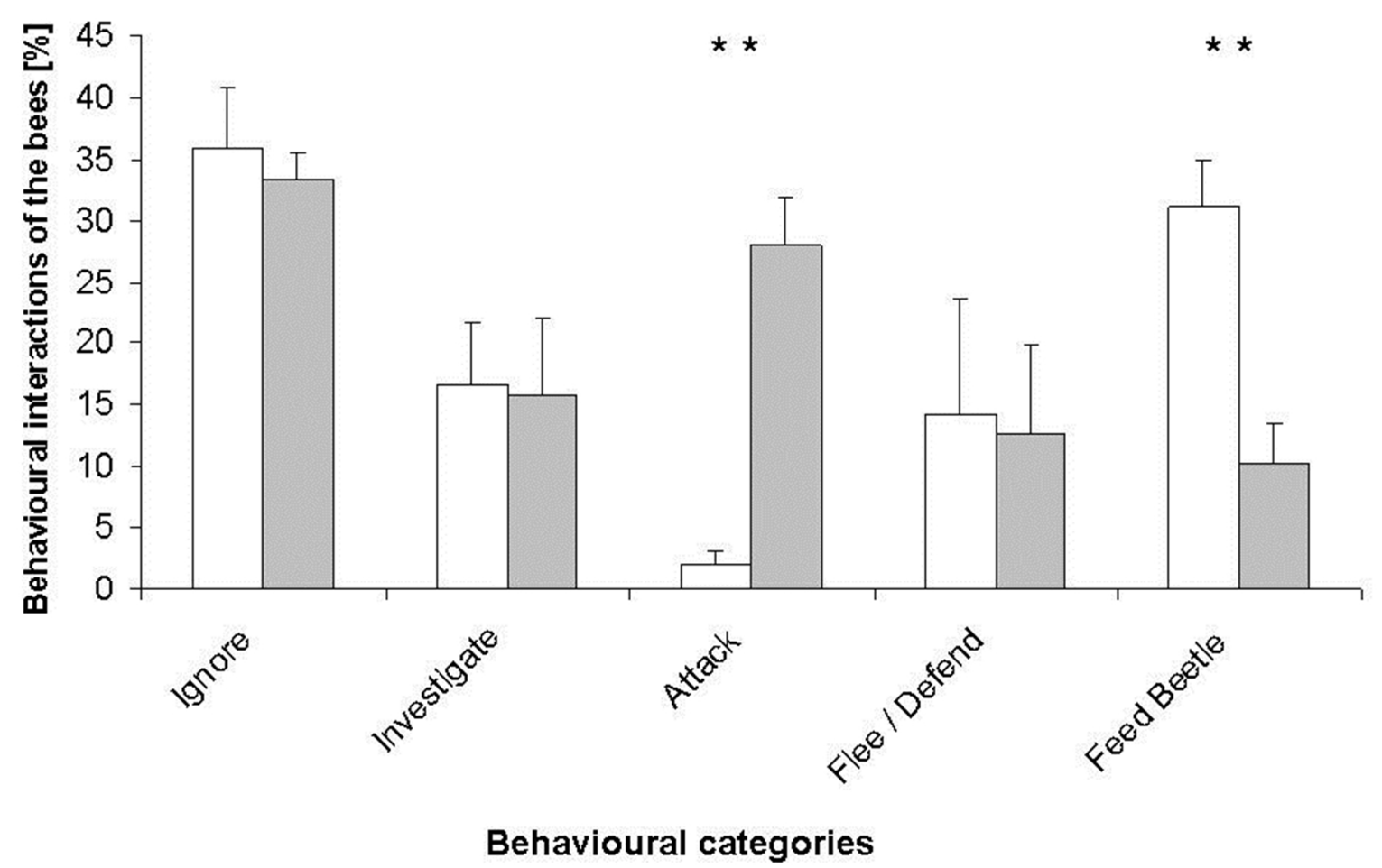

Fig. 1: Mean proportion ( $\pm S T D$ ) of the behavioural interactions of young and old workers towards small hive beetle adults. Means, standard variations and results of the Mann-Whitney $U$ tests are shown (white bars $=$ young callow workers, grey bars $=$ old workers, ${ }^{* *}=p<0.01$ ). 


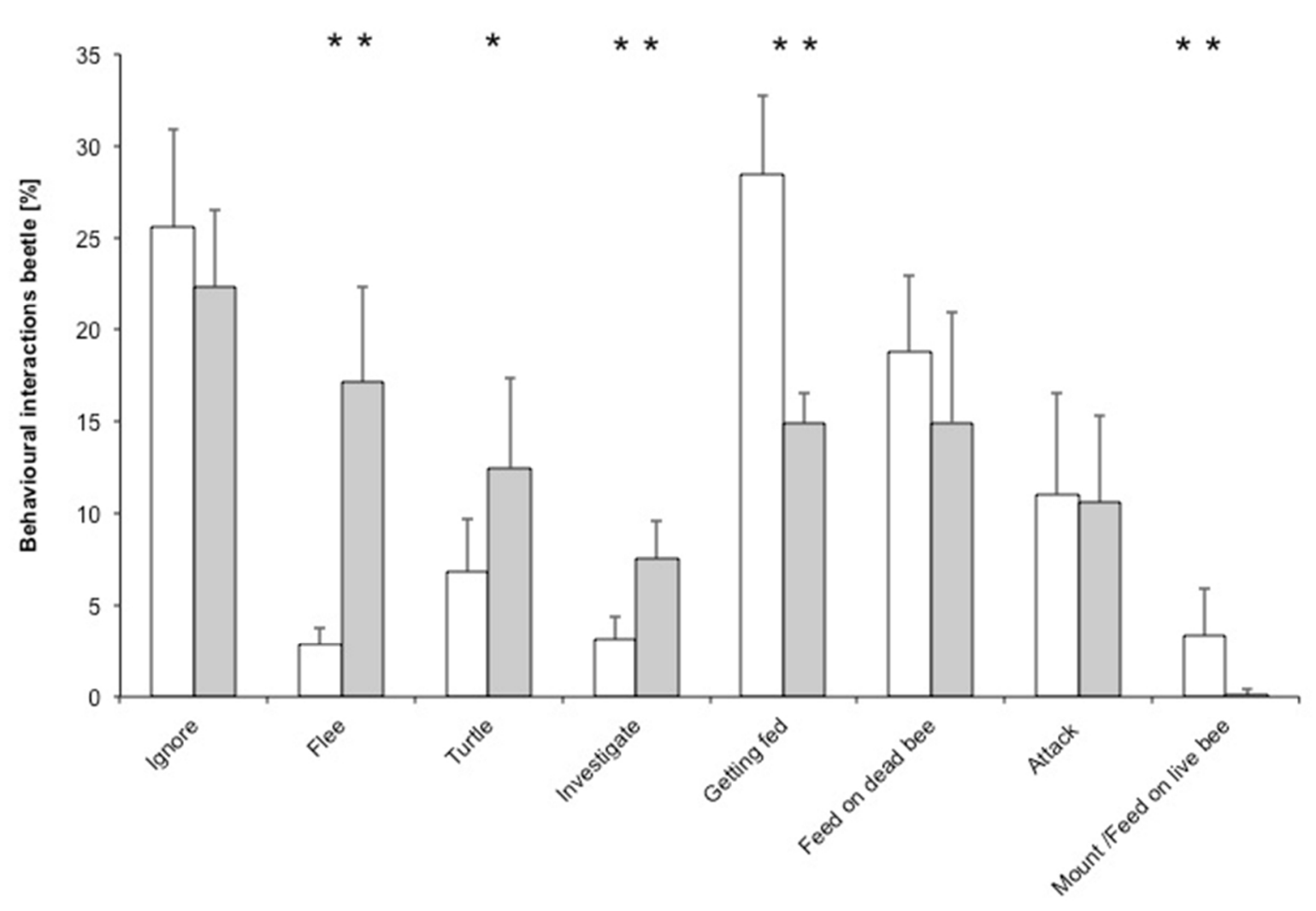

Behavioural categories

Fig. 2: Mean proportion ( \pm STD) of the behavioural interactions of small hive beetles towards young and old workers. Means, standard variations and results of the Mann-Whitney $U$ tests are shown (white bars $=$ young callow workers, grey bars $=$ old workers, ${ }^{*}=p<0.05,{ }^{* *}=p<0.01$ ).

A similar pattern was observed when differentiating the behaviour of the small hive beetles towards the two age groups of workers. Small hive beetles significantly more often fled, investigated or showed the turtle posture when encountering old workers, whereas small hive beetles significantly more often were fed by or mounted young workers (Fig 2). The behavioural interactions between the workers and small hive beetles follow a clear definite sequence (Fig. 3). Workers and beetles either ignored each other or established physical contact mostly by touching parts of the antagonist's body with their antennae (Fig 3.1). Second step is that the workers either attacks or that the beetle starts tapping the mandibles or antennae of the honey bee with its antennae (Fig 3.2, 3.3). That can result either in a trophallactic interaction (Fig 3.4) or the honey bee workers attacks. In the former case, the next 


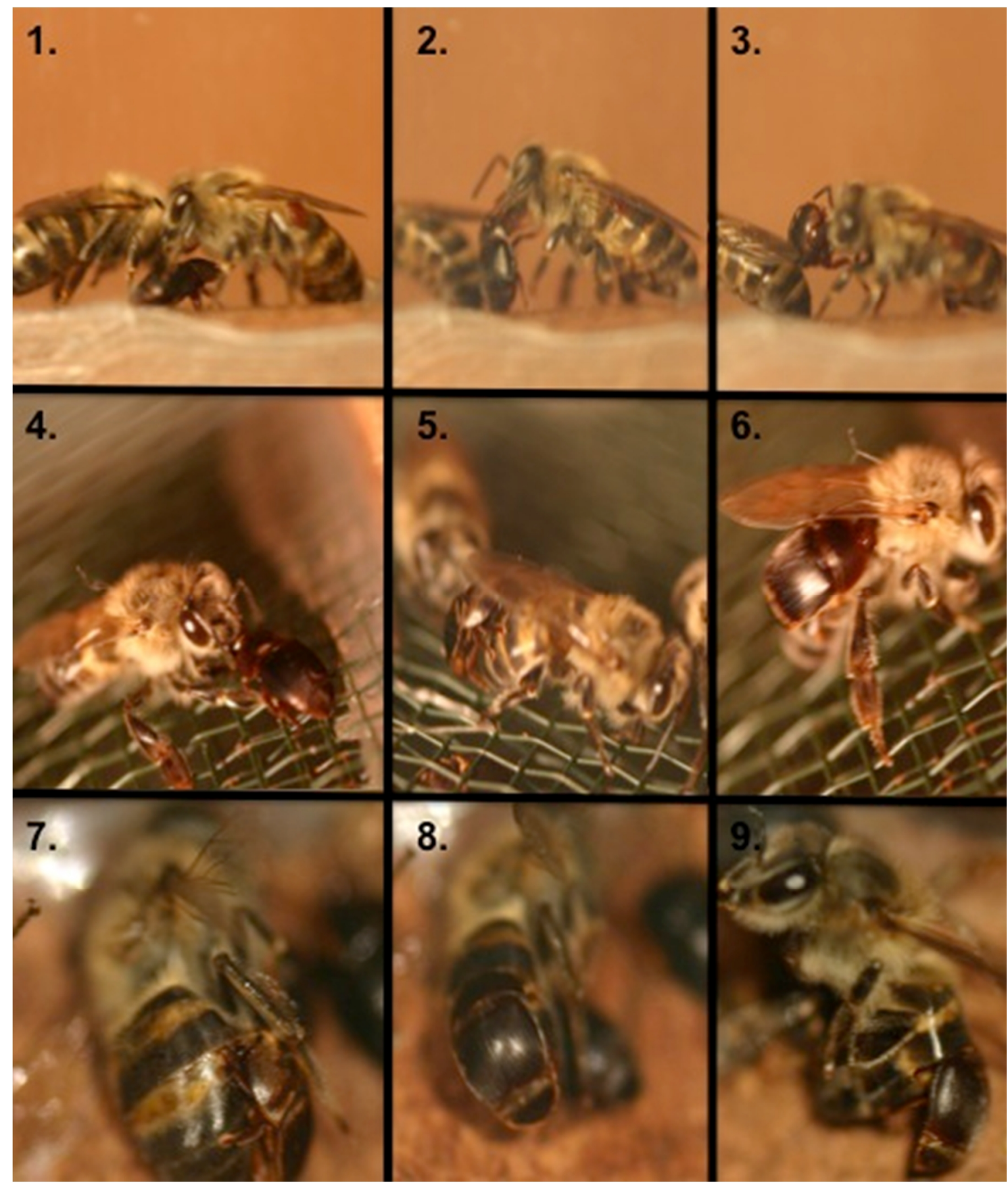

Fig. 3: Behavioural sequence associated with small hive beetle predation on live adult honey bee workers: 1-3) getting into close physical contact, 4) inducing trophallactic feeding, 5+6) mounting the workers' abdomen and cutting with the mandibles through the tissue between the tergites, 7) opening the abdomen between the $3^{\text {rd }}$ and $4^{\text {th }}$ tergite starting at the right corner, 8) cutting through the membrane over the entire abdomen, 9) the beetle partially penetrated into the abdomen.

step is that the beetle attacks and tries to mount the bee (Fig $3.5,3.6$ ). In case that the workers are not successful in shaking-off the beetle, the beetle uses the mandibles to cut in the soft tissue of the intersegmental membrane to open the abdomen (Fig 3.7, 3.8). The abdomen of the bees is then opened, thereby allowing the beetle to feed on the intestines of the bees (Fig. 3.9). 


\section{Discussion}

The differential behaviour of the small hive beetles towards young and old honey bee workers indicates that the beetle is assessing the defensiveness of the host and is adjusting its behaviour accordingly. Indeed, as we showed young workers are more often mounted and attacked than their older nestmates and the mortality of the young workers is significantly higher after 24 hours showing the effect to the SHB predation. The mechanism which the beetles use to assess the defensiveness is most likely the response of the workers towards their probing of the workers, e.g. if the workers attack back or not.

It might well be that the SHB simply assess if the item in front is a suitable food source or not, i.e. if they are attacked first by the workers, they then may never try attacking back. However, beetle behavior is apparently more complex than simply distinguishing edible from inedible items, because SHB and worker constantly interact when workers try to keep SHB away from food stores and brood (Neumann et al., 2001b) and because SHB also provoke trophallaxis from workers (Ellis et al., $2002 b)$. Indeed, part of the initiation of these trophallactic interactions is that the SHB is performing movements back and forward towards the worker and only when rebuffed they adjust their tactic and retreat, otherwise it gets encouraged to approach (Ellis et al., 2002b). This probably provides the SHB with the opportunity to actually register differences in the defensiveness of the opponent rather than just simply discriminating between a suitable food source or not.

The ability of the beetle to assess the defensiveness of its host appears to be adaptive, because after-absconding events often include freshly emerged nestmates left behind (Hepburn et al 1999, Neumann and Hepburn 2011). First, although attacking of young bees might be more risky then feeding on dead bees it seems to be more rewarding, because the nutritional value and water content of an insect which is alive is higher than a corpse in its first stages of decay (Carter et al., 2007). 
Second, female beetles utilising that new food resource might have a head start compared to other beetles in terms of reproduction. Since a healthy African honey bee colony usually prevents the reproduction of small hive beetles (Neumann and Härtel, 2004), the beetles typically have to wait until the colony is getting weak or abandon their nest to feed and reproduce (Neumann et al., 2001b). Under both conditions the remaining resources are limited. By being a facultative predator, beetles exploring that additional food resource trade safety against a higher reward. Moreover, adult beetles, which are utilising the defenceless young workers as a food resource, reduce the direct competition with their own offspring. Beetle larvae feed on pollen, honey stores and brood, which are left by the bees (Neumann et al., 2001a; Ellis et al., 2002a). Also these resources are limited, especially when bees perform prepared absconding (Spiewok et al., 2006), and therefore larvae and adult beetle are competing for these. Obviously, only in such situation it is possible for them to compete, because otherwise the divers age structure of the honeybee colony would result in larvae and beetles being attack by the older cohorts, e.g. larvae actively removed (Neumann and Härtel, 2004). By preying on defenceless young live workers the adult beetle utilizes a food source, which can obviously not be utilised by the beetle larvae, since the larvae is too slow and even the mandibles of a callow worker could penetrate the epidermis of the larvae. This utilization of another food source would also reduce the direct competition for resources between adults and larvae.

In conclusion, small hive beetles can be facultative predators of adult honeybee workers, because they seem to be able to assess the trade-off between safety and food reward. This in line with predators optimising their energy intake (Suraci and Dill, 2011). However other factors like nutritional balance (Toft, 1999) or prey behaviour (Cresswell and Quinn, 2010; Pohl and Foitzik, 2011) also seems to play a role. 
Indeed, the reported behavioural patterns show that the need for a protein source and the level of defensiveness are affecting prey choice.

\section{Acknowledgements}

Financial support was granted by Rhodes University, the National Research Foundation and the University of Pretoria. Appreciation is addressed to Jochen Drescher for technical assistance, Martin Hill and Randall Hepburn for providing laboratory facilities and Randall Hepburn also for commenting on the MS.

\section{References}

Berger-Tal, O., Mukherjee, S., Kotler, B. P., and Brown, J. S. (2010). Complex statedependent games between owls and gerbils. Ecology Lett. 13: 302-310. doi:10.1111/j.1461-0248.2010.01447.x

Brown, J. S., and Kotler, B. P. (2004). Hazardous duty pay and the foraging cost of predation. Ecology Lett. 7: 999-1014.

Carter, D., Yellowlees, D., and Tibbett, M. (2007). Cadaver decomposition in terrestrial ecosystems. Naturwissenschaften 94: 12-24. doi:10.1007/s00114006-0159-1

Cresswell, W., and Quinn, J. L. (2010). Attack frequency, attack success and choice of prey group size for two predators with contrasting hunting strategies. Anim. Behav. 80: 643-648. doi:10.1016/j.anbehav.2010.06.024

Ellis, J. D., Neumann, P., Hepburn, R., and Elzen, P. J. (2002a). Longevity and reproductive success of Aethina tumida (Coleoptera : Nitidulidae) fed different natural diets. J. Econ. Entomol. 95: 902-907.

Ellis, J. D., Pirk, C. W. W., Hepburn, H. R., Kastberger, G., and Elzen, P. J. (2002b). Small hive beetles survive in honeybee prisons by behavioural mimicry. Naturwissenschaften 89: 326-328.

Elzen, P. J., Baxter, J. R., Neumann, P., Solbirg, A. J., Pirk, C. W. W., Hoffman, W., and Hepburn, H. R. (2000). Observations on the small hive beetle in South Africa. Am. Bee J. 140: 304-304.

Elzen, P. J., Baxter, J. R., Neumann, P., Solbrig, A., Pirk, C., Hepburn, H. R., Westervelt, D., and Randall, C. (2001). Behaviour of African and European subspecies of Apis mellifera toward the small hive beetle, Aethina tumida. J. Apicult. Res. 40: 40-41.

Hepburn, H. R., and Radloff, S. E. (1998) Honeybees of Africa. Springer Verlag Berlin, Germany

Hepburn, H. R., Reece, S. L., Neumann, P., Moritz, R. F. A., and Radloff, S. E. (1999). Absconding in honeybees (Apis mellifera) in relation to queen status and mode of worker reproduction. Insectes Soc. 46: 323-326.

Langan, A. M., Pilkingtonb, G., and Wheater, C. P. (2001). Feeding preferences of a predatory beetle (Pterostichus madidus) for slugs exposed to lethal and sublethal dosages of metaldehyde. Entomol. Exp. Appl. 98: 245-248. 
Lima, S. L. (1988). Initiation and Termination of Daily Feeding in Dark-Eyed Juncos: Influences of Predation Risk and Energy Reserves. OIKOS 53: 3-11.

Lundie, A. E. (1940). The small hive beetle, Aethina tumida. Sci. B. U. S. Afr. 220: 519.

Mair, J., and Port, G. R. (2001). Predation by the carabid beetles Pterostichus madidus and Nebria brevicollis is affected by size and condition of the prey slug Deroceras reticulatum. Agr. Forest Entomol. 3: 99-106.

Moritz, R. F. A., Kirchner, W. H., and Crewe, R. M. (1991). Chemical Camouflage of the Death's Head Hawkmoth (Acherontia atropos L.) in Honeybee Colonies. Naturwissenschaften 78: 179-182.

Neumann, P., and Härtel, S. (2004). Removal of small hive beetle (Aethina tumida) eggs and larvae by African honeybee colonies (Apis mellifera scutellata). Apidologie 35: 31-36.

Neumann, P., and Elzen, P. J. (2004). The biology of the small hive beetle ( Aethina tumida , Coleoptera : Nitidulidae): Gaps in our knowledge of an invasive species. Apidologie 35: 229-247.

Neumann, P., and Ellis, J. D. (2008). The small hive beetle (Aethina tumida Murray, Coleoptera : Nitidulidae): distribution, biology and control of an invasive species. J. Apicult. Res. 47: 181-183. doi:Doi 10.3827/lbra.1.47.3.01

Neumann, P., and Hepburn, H. R. (2011). Absconding and mergers of orphaned Cape honeybees. J. Apicult. Res. 50: 165-166.

Neumann, P., Radloff, S. E., Pirk, C. W. W., and Hepburn, H. R. (2003). The behaviour of drifted Cape honeybee workers (Apis mellifera capensis): predisposition for social parasitism? Apidologie 34: $585-590$.

Neumann, P., Schäfer, M. O., Löwe, M., and Ferenz, H. J. (2012). Reproductive physiology of small hive beetle (Aethina tumida, Coleoptera: Nitidulidae). J. Insect Physiol. in review:

Neumann, P., Pirk, C. W. W., Hepburn, H. R., Elzen, P. J., and Baxter, J. R. (2001a). Laboratory rearing of small hive beetle, Aethina tumida (Coleoptera: Nitidulidae). J. Apicult. Res. 40: 111-112.

Neumann, P., Pirk, C. W. W., Hepburn, H. R., Solbrig, A. J., Ratnieks, F. L. W., Elzen, P. J., and Baxter, J. R. (2001b). Social encapsulation of beetle parasites by Cape honeybee colonies (Apis mellifera capensis Esch.). Naturwissenschaften 88: 214-216.

Pirk, C. W. W., Boodhoo, C., Human, H., and Nicolson, S., W. (2010). The importance of protein type and protein to carbohydrate ratio for survival and ovarian activation of caged honeybees (Apis mellifera scutellata). Apidologie 41: $62-72$.

Pohl, S., and Foitzik, S. (2011). Slave-making ants prefer larger, better defended host colonies. Anim. Behav. 81: 61-68. doi:10.1016/j.anbehav.2010.09.006

Schmolke, M. D. (1974) A study of Aethina tumida: The small hive beetle. Thesis: University of Rhodesia (Zimbabwe) Harare, pp 178

Spiewok, S., and Neumann, P. (2006). Cryptic low-level reproduction of small hive beetles in honey bee colonies. J. Apicult. Res. 45: 47-48.

Spiewok, S., Neumann, P., and Hepburn, H. R. (2006). Preparation for disturbanceinduced absconding of Cape honeybee colonies (Apis mellifera capensis Esch.). Insectes Soc. 53: 27-31.

Sunderland, K. D., and Sutton, S. L. (1980). A Serological Study of Arthropod Predation on Woodlice in a Dune Grassland Ecosystem. J. Anim. Ecol. 49: 987-1004.

Suraci, J. P., and Dill, L. M. (2011). Energy Intake, Kleptoparasitism Risk, and Prey Choice by Glaucous-Winged Gulls (Larus glaucescens) Foraging on Sea Stars. The Auk 128: 643-650. doi:10.1525/auk.2011.11105 
Toft, S. (1999). Prey choice and spider fitness. J Arachnol 27: 301-307.

Wilmers, C. C., Crabtree, R. L., Smith, D. W., Murphy, K. M., and Getz, W. M. (2003). Trophic facilitation by introduced top predators: grey wolf subsidies to scavengers in Yellowstone National Park. J. Anim. Ecol. 72: 909-916.

Yusuf, A., Gordon, I., Crewe, R. M., and Pirk, C. W. W. (2013). Prey choice and Raiding Behaviour of the Ponerine ant Pachycondyla analis (Hymenoptera: Formicidae) J. Nat. Hist. in press: 